\title{
Estimation of Potential Greenhouse Gas Emissions from Solid Waste Disposal Sites According to the Climatic Context and Demographic Characteristics of Moroccan Regions
}

\author{
A. Ourhedja ${ }^{1, *}$, S. Labzae $^{2}$, M. N. Bargach ${ }^{1}$ and R. Tadili ${ }^{1}$ \\ ${ }^{I}$ Department of Physics, Laboratory of Solar Energy and Environment, Faculty of Sciences, Mohammed V University in Rabat, P.B. \\ 1014, Rabat - Morocco. \\ ${ }^{2}$ ECOMED, Ain Al Beida, Fès - Morocco.
}

Received 8 June 2019; Accepted 30 May 2021

\begin{abstract}
The amount of biogas that can potentially be generated by municipal solid waste landfills (MSW) in Morocco is estimated using the LandGEM model. The model parameters (annual methane production rate $\mathrm{k}$ and annual methane production potential Lo) are determined taking into account the climatic context of 12 Moroccan regions, the annual mass of waste buried in each region and their composition. By analyzing the monthly averages of temperature, rate of precipitation and potential evapotranspiration in 75 Moroccan cities, a classification of the types of climate of the 12 Moroccan regions is carried out. Correlation relationships between changes in the annual production of municipal solid waste (MSW) and the number of inhabitants are established. Different fractions of fermentable waste made up of the four categories of waste most generated in Morocco (paper and textiles, wood, green waste and organic waste) are examined, and several combinations of these fractions are envisioned. The obtained results show that the total emissions of methane, potentially generated over a period of 30 years (2016-2045) by landfills, would produce on average the equivalent of about 4963248 tons of $\mathrm{C}_{\mathrm{O} 2 \mathrm{e}}$ per year. While its combustion by flaring, or by recovery for the cogeneration of heat and / or electricity, should limit its release into the atmosphere, and would produce on average only about 545911 tons of carbon dioxide per year, i.e. an annual reduction in carbon dioxide emissions of $89 \%$.
\end{abstract}

Keywords: Municipal Solid Waste - Controlled landfills - Methane generation - Reduction of greenhouse gases - Equivalent emissions in Carbone dioxide.

\section{Introduction}

The growing quantities of waste, generated by the demographic expansion of populations in large cities, are beginning to constitute a major challenge that puts pressure on the environment and on the quality of life of populations, and to which local authorities in many countries across the world are increasingly confronted. The harmful consequences of this situation on natural resources, public health and the budget of local communities become over the years an obvious alarming danger that must be managed. If one of the effective means to remedy this situation, and reduce the serious repercussions which result from it, is the burying of the waste in landfill technical centers (TEC), the degradation of the organic matter contained in the buried waste results in the production of large quantities of gas, mainly composed of methane $\mathrm{CH}_{4}$ and carbon dioxide $\mathrm{CO}_{2}$. Other gases are also present in small quantities such as water vapour $\mathrm{H}_{2} \mathrm{O}$, nitrogen $\mathrm{N}_{2}$, hydrogen $\mathrm{H}_{2}$, oxygen $\mathrm{O}_{2}$, hydrogen sulfide $\mathrm{H}_{2} \mathrm{~S}$, as well as silicones and volatile fatty acids. (AGV). The methane produced by TECs is a greenhouse gas (GHG) which strongly contributes to global warming [1]. Its capture makes it possible to reduce the greenhouse effect resulting from its diffusion in the atmosphere, either by burning it in a flare, or by valorising it energetically by combustion in cogeneration

*E-mail address: ourhedja.asmae@gmail.com ISSN: 1791-2377 (C) 2021 School of Science, IHU. All rights reserved. doi:10.25103/jestr.145.09 systems. Several factors are however responsible for conditioning the amount of methane applied by TECs. These factors include the mode of landfilling, the quantity and age of the waste landfilled, their organic matter composition and the climatic conditions of the landfill site (temperature, humidity, precipitation and atmospheric pressure). The objective of our study is to contribute to the decision-making aid for the optimization of waste management and recovery in Morocco. The potential for landfill methane production in 12 Moroccan regions is inventoried taking into account the climatic context of each region, the annual mass of buried waste and its composition. In addition, the total equivalent $\mathrm{CO}_{2}$ emissions that could be avoided by the combustion of the methane generated by the releases are quantified.

\section{Methodology}

For the modeling and analysis of the biogas generation potential of landfills, eventually installed in the 12 Moroccan regions, we used the LandGEM model, developed by the United States Environmental Protection Agency (US EPA) [2] for the estimation of the amount of biogas generated by TECs. This model, which is based on the kinetics of decomposition of waste, allows us to consider several categories of buried matter, and therefore has a multiphasic structure susceptible to produce results with sufficient prediction precision. 
2.1 Equation of the decomposition rate of the LandGEM Model

The first order decomposition rate equation used in the LandGEM [3] model is as follows:

$Q_{C H_{4}}=\sum_{i=1}^{n}\left(\sum_{j=0.1}^{1} k \times L_{o} \times\left(\frac{M_{i}}{10}\right) \times e^{-k \times t_{i j}}\right)$

where: $Q_{C H 4}$ is the annual methane production in the calculation year (in $\mathrm{m}^{3} /$ year); $k$ is the annual methane production rate (in year ${ }^{-1}$ ); $L_{o}$ is the annual methane generation potential (in $\mathrm{m}^{3} /$ ton); $M_{i}$ is the mass of waste accepted in the $\mathrm{i}^{\text {th }}$ year (in tons/year); $i$ is the one-year time increment; $j=0.1$ is the year increment; $n$ is the difference between the year of the calculation and the initial year of waste acceptance; $t_{i j}$ is the age of the $\mathrm{j}^{\text {th }}$ section of the waste mass $\mathrm{M}_{\mathrm{i}}$ accepted in the $\mathrm{i}^{\text {th }}$ year.

The relevant parameters of Eq. 1 are the annual methane production rate $k$ and the annual methane generation potential Lo [4]. For each region, these parameters are determined taking into account the climatic context of the region, the annual mass of buried municipal solid waste (MSW) and their composition, in relation to the demographic characteristics of its population.

\subsection{Climate context of Moroccan regions}

The climate types of 75 Moroccan cities, concerned by the last national census of 2014 [5], were established in accordance with the 2006 (IPCC) Guidelines for national greenhouse gas inventories [4]. According to these guidelines, two different types of regional climates are to be considered depending on the Mean Annual Temperature (MAT) of the region: if MAT $\leq 20^{\circ} \mathrm{C}$, the climate is of the Boreal and Temperate type, if MAT $>20^{\circ} \mathrm{C}$, it is therefore of the Tropical type. For Boreal and Temperate climates, and based on the ratio of Mean Annual Precipitation (MAP) and Potential Evapotranspiration (PET) of the considered city, two cases are to be distinguished: the climate is of the Dry Boreal and Temperate (DBT) type if MAP/PET $<1$, while it is of the Wet Boreal and Temperate (WBT) type if MAP/PET $>1$. Similarly, according to the Mean Annual Precipitation rate (MAP), two cases should also be considered for Tropical type climates: if MAP $<1000 \mathrm{~mm}$, the climate is of the Dry Tropical (DT) type, and if MAP $\geq 1000 \mathrm{~mm}$, it is of the Moist and Wet Tropical (MWT) type.

For the 75 Moroccan cities, the mean annual values (MAT) and (MAP) have been respectively calculated from the monthly averages provided by the site Climate-Data.org [6]. The potential evapotranspiration (PET) was calculated for each city by the Thornthwaite method [7], taking into account the duration of the month and the theoretical number of hours of sunshine, in relation to the latitude of the location.

\subsection{Demographic characteristics of the Moroccan population}

According to the results of the last demographic census of Morocco [5], the total Moroccan population in 2014 included around 33.8 million inhabitants extended over 12 regions (urban and rural environments combined). About $70.2 \%$ of this population is grouped in five regions, which are Casablanca-Settat (20.3\%), Rabat-Salé-Kénitra (13.5\%), Marrakech-Safi (13.4\%), Fès-Meknès (12.5\%), and TangerTétouan-Al Hoceima (10.5\%), with around $61.3 \%$ in urban environment, and $38.7 \%$ in rural one. The Analysis of the results of a study on regional demographic prospects in Morocco [8], evaluated using a logistic function where the qualitative variable to be explained is based on real data collected between 2005 and 2014, shows that by 2030, the total Moroccan population will reach approximately 39.3 million inhabitants, representing a demographic increase of approximately $16.3 \%$. This increase will be accompanied by socio-economic development of the regions, with development kinetics differing from one region to another and from one year to the next.

\subsection{Annual masses of Municipal Solid Waste (MSW)}

In the absence of complete data on the annual production of MSW in Morocco, and noting that the evolution of the number of inhabitants follows a strictly increasing law, we consider that at the regional level, the evolution of the production of MSW is proportional to the evolution of the number of inhabitants of the population. In order to assess the relevance of a correlation relationship between these two parameters, we have performed a statistical adjustment of the point cloud $(x, y)$, where $x$ is the value of the variable $X$ designating the annual number of inhabitants of a region, and $y$ the value of the variable $Y$ designating the corresponding annual rate of MSW production. The only available data used for this adjustment are the forecast data for the two years 2015 and 2030, reported in a summary report on the National strategy for the reduction and recovery of waste [9].

Assuming that the annual increase in waste production is regular between 2015 and 2030, and using data provided by the High Commission for Planning (HCP) [8], relating to the inhabitant number projection during the same period, the variation curves of the rate of MSW production according to the number of inhabitants are deduced for each year from the following equation:

$Y_{i+1}(X)=Y_{i}(X)+\frac{Y_{b}(X)-Y_{a}(X)}{n-1}$

where: $Y_{a}(X)$ and $Y_{b}(X)$ are the adjustment curves of the data relative to the two years 2015 and 2030, respectively, $n$ $=16$ is the total years from 2015 to 2030 , and $i$ is the rank of year between 2015 where $i=0$, and 2030 where $i=15$.

\subsection{Composition of MSW}

One of the main factors influencing gas emissions from landfills is the composition waste, characterized by the amount of degradable organic carbon it contains. Depending on the nature of the waste buried (size, density, humidity, etc.), the composition can vary considerably from one region to another, and from one season to another. Based on the results of characterization studies of MSW carried out in Morocco [10], [11], [12], [13] and [14], we consider that the fraction of fermentable waste in the total mass of buried MSW mainly consists of the following four categories of the most generated waste: paper and textiles, wood, green waste and organic waste. For each category, several fractions FRi (\%), among those most likely, are considered (see Tab.1). The conjugation of each of these fractions with each of the fractions of the other categories constitutes a singular fermentable fraction $F R(\%)=\sum_{i=1}^{i=4} F R(\%)$ of different composition. A set of 2480 combinations of different fractions have been examined. 
Table 1. Envisaged fractions of waste composition

\begin{tabular}{l|l|c}
\hline Type of waste & Envisaged fractions (\%) & Total \\
\hline Paper and textiles & $8-9-10-11-12$ & 5 \\
Wood & $0.5-1.0-1.5-2.0$ & 4 \\
Green waste & $0.2-0.3-0.4-0.5$ & 4 \\
Organic waste & De 50 à 80\% par pas de $1 \%$ & 31 \\
\hline Total number of envisaged compositions $=(5 \times 4 \times 4 \times 31)$ & 2480 \\
\hline
\end{tabular}

\subsection{Methane generation rate $\mathrm{k}$}

The annual rate of generation of methane $\mathrm{k}$, determined according to the climatic context of the region and the composition of the landfilled waste, is calculated from the following relation:

$k=\frac{\sum_{i=1}^{n} F R_{i} \times k_{i}}{F R}$

where: $F R_{i}(\%)$ is the proportion of type $i$ of waste in the fraction of fermentable waste; FR (\%) is the total fraction of fermentable waste in the mass of MSW; $k_{i}\left(\right.$ year $\left.^{-1}\right)$ is the methane generation rate of the waste fraction $F R i$, linked to type $i$ of waste and type of climate of the landfill site; and $n$ is the number of waste categories.

\subsection{Methane generation potential $\mathbf{L}_{0}$}

The methane generation potential $L_{o}$ (in $\mathrm{m}^{3}$ of $\mathrm{CH}_{4}$ per ton of waste) is assessed according to several parameters from the following relationship [15]:

$L_{o}=\frac{F \times D O C \times D O C_{f} \times M C F \times 16}{12 \times \rho_{C H 4} \times 10^{-3}}$

where: $F$ is the fraction of the $\mathrm{CH}_{4}$ volume contained in the landfill produced gas (by default, $F=60 \%$ ) [15]; $D O C_{f}$ is the decomposable fraction of degradable organic carbon produced by waste, (by default, $D O C_{f}=50 \%$ ) [15]; $M C F$ is the correction factor for methane linked to technical landfill and waste storage conditions (by default, $M C F=1$ for controlled landfills,) [15]; $\rho_{C H 4}=0.7162 \mathrm{~kg} / \mathrm{m}^{3}$ is the density of methane; $12 / 16$ is the molecular weight ratio $\mathrm{CH}_{4} / \mathrm{C} ; D O C$ $(\mathrm{kg} / \mathrm{kg})$ is the degradable organic carbon rate, calculated for each type $i$ of waste by weighting the degradable organic carbon rate $D O C_{i}$ (in $\mathrm{kg}$ of carbon per $\mathrm{kg}$ of fermentable waste), affected by the $F R_{i}(\%)$ fraction of waste, from the following relationship:

$D o c=\frac{\sum_{i=1}^{i=4} F R_{i} \times D O C_{i}}{F R}$

2.8 Emissions in carbon dioxide equivalent $\mathrm{CO}_{2} \mathrm{e}$

According to the First Assessment Report (FAR) of the IPCC [16], the emission in equivalent carbone dioxide $\mathrm{CO}_{2 \mathrm{e}}$ is an indicator used to compare the quantity emitted of carbon dioxide, which would cause the same integrated radiative forcing, over a given period, as an emitted quantity of one or several greenhouse gases (GHG). The conversion of GHG emissions into equivalent $\mathrm{CO}_{2 \mathrm{e}}$ is carried out using its global warming power (GWP) over the same period. The global warming potential of methane being 25 times greater than that of $\mathrm{CO}_{2}$ at 100 years $[17 ; 18]$, the emission in $\mathrm{CO}_{2}$ equivalent of methane generated by a MSW landfill and potentially dispersed without any combustion in the atmosphere, is calculated from the equation:

$\mathrm{CO}_{2 e}\left(\right.$ unburned $\left.\mathrm{CH}_{4}\right)=25 \times Q_{\mathrm{CH}_{4}} \times \rho_{\mathrm{CH}_{4}} \times 10^{-3}$ where: $\mathrm{CO}_{2 e}$ (unburned $\mathrm{CH}_{4}$ ) (tons/year) is the carbon dioxide equivalent of the generated methane; $Q_{\mathrm{CH}_{4}}\left(\mathrm{~m}^{3} /\right.$ year $)$ is the estimated volume of generated methane; and $\rho_{\mathrm{CH}_{4}}=$ $0.7162 \mathrm{~kg} / \mathrm{m}^{3}$ is the density of methane.

The potential emissions of carbon dioxide from the combustion of generated methane in a gas flare or in a boiler correspond to the mass of carbon dioxide produced by the complete combustion of methane according to the following combustion equations:

$\mathrm{CH}_{4}+2 \mathrm{O}_{2} \rightarrow \mathrm{CO}_{2}+2 \mathrm{H}_{2} \mathrm{O}$

or: $16 \mathrm{CH}_{4}(\mathrm{~kg})+64 \mathrm{O}_{2}(\mathrm{~kg}) \rightarrow 44 \mathrm{CO}_{2}(\mathrm{~kg})+$ $36 \mathrm{H}_{2} \mathrm{o}(\mathrm{kg})$

The mass of carbon dioxide produced per mass unit of methane burned is therefore:

$m \mathrm{CO}_{2}=\frac{44}{16}=2.75(\mathrm{~kg} / \mathrm{kg})$

and the potential carbon dioxide emissions from the combustion of methane generated by the MSW landfill is calculated (in tons/year) from the following equation:

$\mathrm{CO}_{2 e}\left(\right.$ burned $\left.\mathrm{CH}_{4}\right)=\mathrm{mCO}_{2} \times Q_{\mathrm{CH}_{4}} \times \rho_{\mathrm{CH}_{4}} \times 10^{-3}$

\section{Results and discussions}

The classification by type of climate of the 75 Moroccan cities concerned by the study shows that:

- 63 cities correspond to the Dry Boreal and Temperate (DBT) type climate;

- 10 cities correspond to the Dry Tropical (DT) type climate, nine of which belong to the Sahairan regions of Southern Morocco (Assoured, Assa-Zag, Boujdour, Dakhla, Es Smara, Tan-Tan, Taroudanet, Tata and Zagora), and one located in the North of Morocco (Sidi Kacem);

- 2 mountainous cities (Chefchaouen and Ifrane) correspond to the Wet Boreal and Temperate (WBT) type climate;

- None city corresponds to the Moist and Wet Tropical (MWT) type climate.

These results show that around $84 \%$ of Moroccan cities correspond to the (DBT) climate type, and $12 \%$ to the (DT) climate one. This led us to define, for the 12 Moroccan regions, the global type of climate to which they belong. Tab. 2 presents the inventory of climate types for each region, and Fig. 1 shows the location of Moroccan regions and their type of climate. 


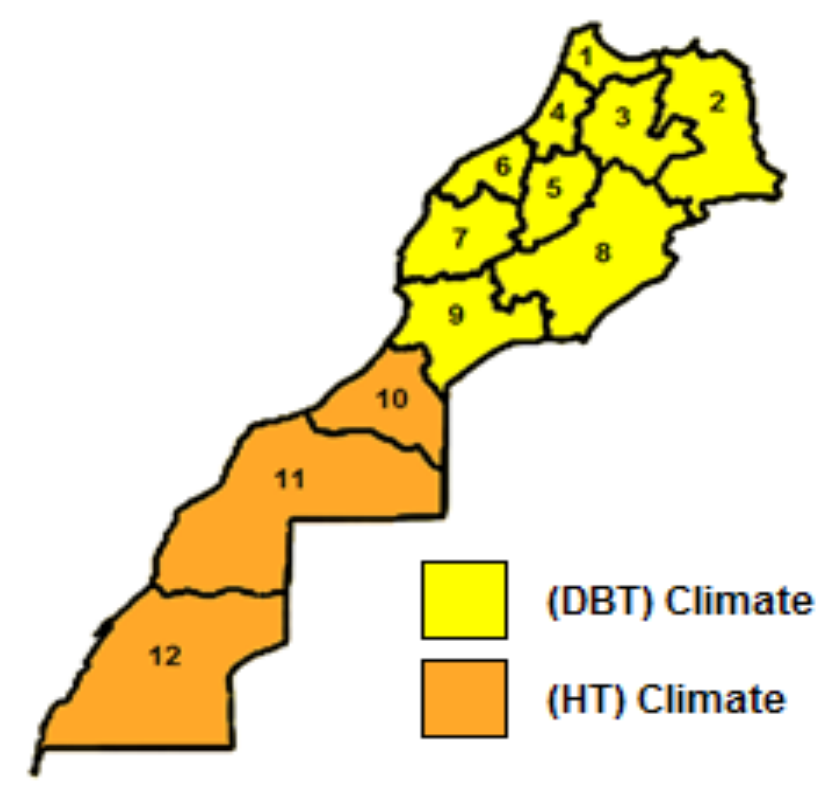

Fig. 1. Location of Moroccan regions and their type of climate.

The data used for the adjustment of the point cloud $(x, y)$ are presented in the following Tab.3:

The Analysis of these data shows that at the national level, the increase in the number of inhabitants from approximately 34.125 million inhabitants in 2015, to approximately 39.330 million inhabitants by 2030 , will be accompanied by an increase in the mass of produced MSW from about 5.936 million tons/year in 2015, to about 8.819 million tons/year by 2030. This corresponds to an average daily increase per inhabitant from $0.476 \mathrm{~kg}$ /inhabitant/day in 2015 to 0.620 $\mathrm{kg} / \mathrm{inhabitant} /$ day in 2030. At the regional level, data analysis indicates that the annual mass of produced MSW waste is proportional to the number of inhabitants.

$\underline{\text { Table 2. Types of climates in Moroccan regions. }}$

\begin{tabular}{l|c}
\hline Region & Type of climate \\
\hline 1 - Tanger-Tetouan-Alhoceima & DBT \\
2 - Oriental & DBT \\
3 - Fès-Meknès & DBT \\
4 - Rabat-Salé-Kénitra & DBT \\
5 - Bénni Mellal-Khénifra & DBT \\
6 - Grand Casablanca-Settat & DBT \\
7 - Marrakech-Safi & DBT \\
- Drâa-Tafilalet & DBT \\
9 - Souss-Massa & DBT \\
10 - Guelmim-Oued Noun & HT \\
11 - Laayoune-Sakia El Hamra & HT \\
12 - Eddakhla-Oued Eddahab & HT \\
\hline
\end{tabular}

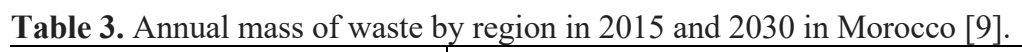

\begin{tabular}{l|r|r|r|r|r|r}
\hline & \multicolumn{3}{|c|}{ Year 2015 } & \multicolumn{3}{c}{ Year 2030 } \\
\cline { 2 - 7 } & Population & \multicolumn{2}{|c|}{ MSW } & Population & \multicolumn{2}{c}{ MSW } \\
\hline Regions & (capita/an) & (ton/an) & (kg/capita/day) & (capita/an) & (ton/an) & (kg/capita/day) \\
\hline Tanger-Tetouan-Alhoceima & 3591289 & 624356 & 0.476 & 4215906 & 1050240 & 0.683 \\
Oriental & 2331198 & 431690 & 0.507 & 2725106 & 603490 & 0.607 \\
Rès-Meknès & 4258822 & 745694 & 0.480 & 4640286 & 1064517 & 0.629 \\
Bénni Mellal-Khénifra & 4619414 & 948262 & 0.562 & 5294469 & 1373363 & 0.711 \\
Grand Casablanca-Settat & 2532789 & 355218 & 0.384 & 2736214 & 470274 & 0.471 \\
Marrakech-Safi & 6934558 & 1484755 & 0.587 & 8301621 & 2211581 & 0.730 \\
Drâa-Tafilalet & 4554780 & 564340 & 0.339 & 5142271 & 830970 & 0.443 \\
Souss-Massa & 1642644 & 147943 & 0.247 & 1773240 & 199463 & 0.308 \\
Guelmim-Oued Noun & 2704735 & 438931 & 0.445 & 3315234 & 681070 & 0.563 \\
Laayoune-Sakia El Hamra & 435230 & 75996 & 0.478 & 464878 & 132751 & 0.782 \\
Eddakhla-Oued Eddahab & 372034 & 89626 & 0.660 & 456582 & 131317 & 0.788 \\
Total & 147377 & 29580 & 0.550 & 264178 & 69998 & 0.726 \\
\hline
\end{tabular}

The adjustment curves obtained for the two years 2015 and 2030, presented in Fig.2 below, have the respective equations:

$$
\begin{aligned}
& Y_{a}(X)=0.03053+0.09554 \times X+0.01611 \times X^{2} \\
& Y_{b}(X)=0.03128+0.14605 \times X+0.01404 \times X^{2}
\end{aligned}
$$

where $Y_{a}(X)$ and $Y_{b}(X)$ are expressed in millions of tons per year of MSW, and $X$ in millions of inhabitants.
The respective coefficients of determination obtained are satisfactory $\left(R^{2}=0.976\right.$ for the year 2015 , and $R^{2}=0.978$ for the year 2030), which shows the existence of a very good correlation relationships between the variables $X$ and $Y$, independently of the regions. The increasing difference observed between the two curves is explained by an increased production of MSW, due to an improvement in the lifestyle of the populations. 


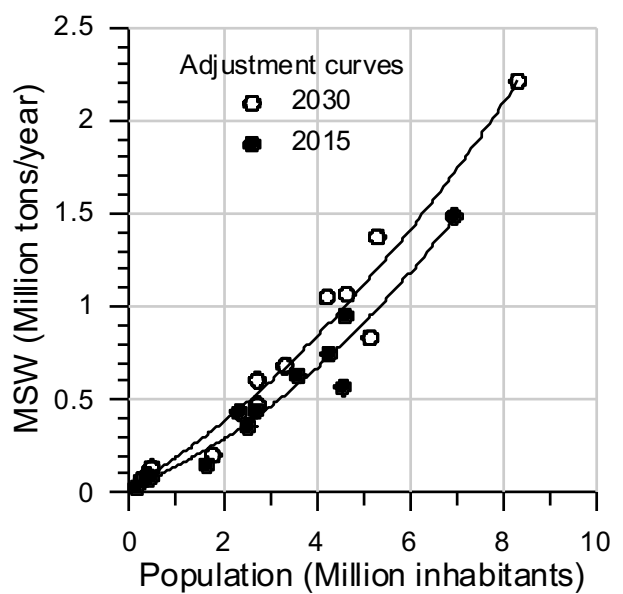

Fig. 2. Adjustment curves for the evolution of the mass of MSW as a function of the number of inhabitants of Moroccan regions, for the two years 2015 and 2030 .
For the other years between 2016 and 2030, the variation curves of the rate of MSW production according to the number of inhabitants are deduced from Eq.2 above. By expressing these curves in the following generic form:

$Y_{i}(X)=a_{i}+b_{i} \times X+c_{i} \times X^{2}$

the coefficients $a_{i}, b_{i}$ and $c_{i}$ are calculated for each year $i$ using the regional data relating to the number of inhabitants [8]. Tab. 4 below gives the annual values of these coefficients.

For the both (DBT) and (DT) climate types and for each category taken apart from buried fermentable waste (paper and textiles, wood, green waste and organic waste), the average values of the rate $k_{i}$ of methane generation, recommended by default by the IPCC [4], are given in the following Tab.5:

Table 4. Coefficients of the annual MSW adjustment curves as a function of the number of inhabitants for the period (2015 2030).

\begin{tabular}{c|c|c|c}
\hline Year & $\mathbf{a}_{\mathbf{i}}$ & $\mathbf{b}_{\mathbf{i}}$ & $\mathbf{c}_{\mathbf{i}}$ \\
\hline 2015 & 0.03053 & 0.09554 & 0.01611 \\
2016 & 0.03058 & 0.09890 & 0.01597 \\
2017 & 0.03063 & 0.10227 & 0.01583 \\
2018 & 0.03068 & 0.10564 & 0.01569 \\
2019 & 0.03073 & 0.10901 & 0.01556 \\
2020 & 0.03078 & 0.11238 & 0.01542 \\
2021 & 0.03083 & 0.11574 & 0.01528 \\
2022 & 0.03088 & 0.11911 & 0.01514 \\
2023 & 0.03093 & 0.12248 & 0.01501 \\
2024 & 0.03098 & 0.12585 & 0.01487 \\
2025 & 0.03103 & 0.12921 & 0.01473 \\
2026 & 0.03108 & 0.13258 & 0.01459 \\
2027 & 0.03113 & 0.13595 & 0.01445 \\
2028 & 0.03118 & 0.13932 & 0.01432 \\
2029 & 0.03123 & 0.14269 & 0.01418 \\
2030 & 0.03128 & 0.14605 & 0.01404 \\
\hline
\end{tabular}

Table 5. Average annual rate ki of methane generation according to the type of climate.

\begin{tabular}{|c|c|c|c|}
\hline \multirow[t]{2}{*}{ Degradation speed } & \multirow[t]{2}{*}{ Nature of waste } & \multicolumn{2}{|c|}{$k_{i}\left(\right.$ year $\left.^{-1}\right)$} \\
\hline & & DBT & HT \\
\hline Slow & $\begin{array}{l}\text { Paper and textiles } \\
\text { Wood }\end{array}$ & $\begin{array}{l}0.040 \\
0.020\end{array}$ & $\begin{array}{l}0.050 \\
0.030\end{array}$ \\
\hline Average & Green waste & 0.050 & 0.065 \\
\hline Fast & Organic waste & 0.065 & 0.085 \\
\hline
\end{tabular}

Table 6. Average annual rate k of methane generation by type of climate.

\begin{tabular}{c|c}
\hline Climate type & $\mathbf{k}\left(\right.$ year $\left.^{-1}\right)$ \\
\hline DBT & 0.0609 \\
HT & 0.0794 \\
\hline
\end{tabular}

In the case where the fermentable waste buried is considered in bulk, and according to its composition, the average annual rate of production of methane $k$ is determined by weighting from Eq.3 above. For each of the 2480 compositions of FR (\%) fractions of the examined fermentable waste, and for each type of climate, the 2480 values of the annual rate of production of methane $k$ are averaged, the obtained results are presented in Tab. 6 below.

For the two types of climate, the frequency distribution histograms presented in Fig. 3 show good dispersions of the $k$ values around the average. For the DBT type climate, $k$ varies between 0.0588 and $0.0622\left(\right.$ year $\left.^{-1}\right)$, with a standard deviation
$\sigma_{D B T}=0.0007\left(\right.$ year $\left.^{-1}\right)$, and for the DT type climate, $k$ varies between 0.0794 and 0.0815 (year $\left.{ }^{-1}\right)$, with a standard deviation $\sigma_{D T}=0.0009\left(\right.$ year $\left.^{-1}\right)$.

For the four concerned categories of waste, the average values of the degradable organic carbon rate $D O C_{i}$, recommended by default by the IPCC [4], are given in Tab.7 below.

The annual emissions $\left(Q_{\mathrm{CH} 4}\right)$ of methane generated by the waste disposal sites, supposed to be installed in each of the 12 Moroccan regions, are determined from Eq.1 of the LandGEM model. The results are used to calculate the annual masses $\mathrm{CO}_{2 e}$ of equivalent emissions of carbon dioxide from methane in the case where it is released into the atmosphere without combustion (from Eq.6), and the annual masses $m \mathrm{CO}_{2}$ of emissions of carbon dioxide, from combustion of methane generated by landfills (from Eq.9). The values of the average annual masses $\mathrm{CO}_{2 e}$ and $\mathrm{mCO}_{2}$ emissions over a period of 30 years $(2016$ - 2045) are presented in Tab.8. A 
comparison of these values shows that the combustion of methane generated by MSW waste disposal sites reduces carbon dioxide emissions by about $89 \%$, compared to the equivalent carbon dioxide emissions of methane.
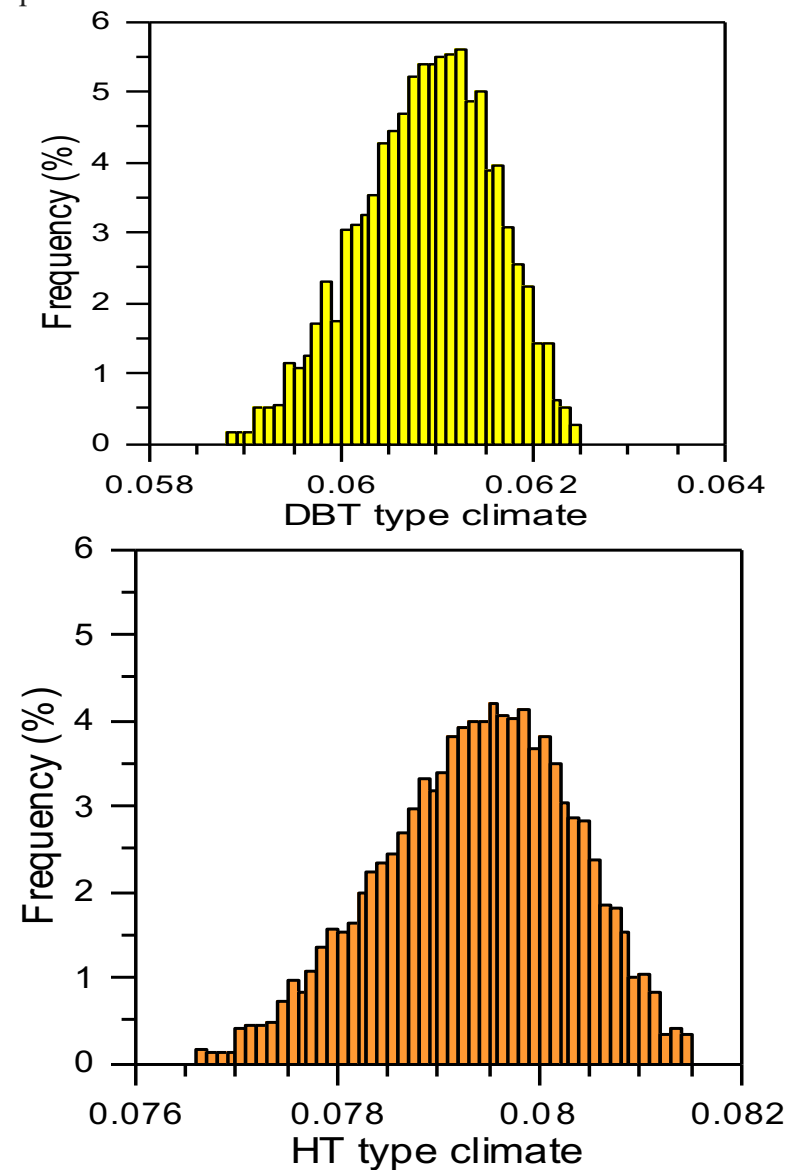

Fig. 3. Histograms of distribution of the annual methane production rate

Table 8. Average annual emissions over a period of 30 years (2016 - 2045) of $\mathrm{CO}_{2 \mathrm{e}}$ and $\mathrm{mC}_{\mathrm{O} 2}$ of methane in the $12 \mathrm{Moroccan}$ regions.

\begin{tabular}{l|r|r|r}
\hline Regions & $\begin{array}{c}\mathbf{C H}_{\mathbf{4}} \text { emissions } \\
\text { (ton/year) }\end{array}$ & $\begin{array}{c}\mathbf{C O}_{\mathbf{2 e}} \text { emissions } \\
\text { (ton/year) }\end{array}$ & $\begin{array}{c}\mathbf{m C O}_{\mathbf{2}} \text { emissions } \\
\text { (ton/year) }\end{array}$ \\
\hline Tanger-Tetouan-Alhoceima & 19781 & 494934 & 54397 \\
Oriental & 11615 & 290385 & 31942 \\
Fès-Meknès & 23469 & 586720 & 64539 \\
Rabat-Salé-Kénitra & 27065 & 676637 & 74430 \\
Béni Mellal-khénifra & 12274 & 306845 & 33753 \\
Grand Casablanca-Settat & 49296 & 1232399 & 135564 \\
Marrakech-Safi & 26285 & 657124 & 72284 \\
Drâa-Tafilalet & 7598 & 189961 & 20896 \\
Souss-Massa & 14246 & 356149 & 39176 \\
Guelmim-Oued Noun & 2669 & 66730 & 7340 \\
Laâyoune-Sakia El Hamra & 2526 & 63140 & 6945 \\
Eddakhla-Oued Eddahab & 1689 & 42224 & 4645 \\
\hline Total & $\mathbf{1 9 8 5 1 3}$ & $\mathbf{4 9 6 3 2 4 8}$ & $\mathbf{5 4 5 9 1 1}$ \\
\hline
\end{tabular}

\section{Conclusion}

In accordance with the criteria defined by the 2006 guidelines (IPCC) for national greenhouse gas inventories [4], the classification by type of climate of the 75 Moroccan cities concerned by the study shows that around $84 \%$ of Moroccan cities correspond to a dry and temperate boreal type climate (DBT), and $12 \%$ to a dry tropical climate (DT). For each type of climate, different compositions of fermentable waste made up of the four categories of solid household waste most generated in Morocco (paper and textiles, wood, green waste
For each of the 2480 fractions of different compositions of fermentable waste, the average degradable organic carbon level is calculated from Eq.5. The values obtained, included between 0.1608 and $0.1883(\mathrm{~kg} / \mathrm{kg})$, are averaged, and the following average value obtained will be used as the average value of the degradable organic carbon content:

$D O C=0.1726(\mathrm{~kg} / \mathrm{kg})$.

The methane generation potential $L_{o}$, determined from Eq.4 above, has then the value:

$L o=96.4\left(\mathrm{~m}^{3} /\right.$ ton $)$.

Table 7. Default values of the average degradable organic carbon rate DOCi.

\begin{tabular}{l|c}
\hline Nature of waste & DOC $_{\mathbf{i}}(\mathbf{k g} / \mathbf{k g})$ \\
\hline Paper and textiles & 0.350 \\
Wood & 0.420 \\
Green waste & 0.200 \\
Organic waste & 0.140 \\
\hline
\end{tabular}

Analysis of these results shows that, over a 30-year period (2016 - 2045), if the methane generated by the MSW landfills is dispersed in the atmosphere, the equivalent annual carbon dioxide emissions will vary on average between a maximum of 1232399 tons/year for the Casablanca-Settat Region, and a minimum of 42224 tons/year for the Eddakhla-Oued Eddahab Region. Total national emissions would be 4963 248 tons/year of $\mathrm{CO}_{2}$. If the methane generated is burned, carbon dioxide emissions from combustion would be reduced by $89 \%$ compared to the equivalent $\mathrm{CO}_{2}$ emissions of methane.

and organic waste) are examined. The nonlinear correlations obtained between the variation in the production rate of MSW and the number of inhabitants show different kinetics of variation, which can be explained by the difference in production of MSW per inhabitant and per day when passing from one region to the other. The average values of the annual rate of methane production $\mathrm{k}$ obtained are $\mathrm{k}=0.0609 \mathrm{year}^{-1}$ for the DBT type climate, and $\mathrm{k}=0.0794$ year $^{-1}$ for the DT type one. The methane generation potential Lo $=96.4\left(\mathrm{~m}^{3} /\right.$ ton). 
The results obtained show that the average annual $\mathrm{CO}_{2 \mathrm{e}}$ equivalent emission of methane production from landfills in Morocco is approximately 4963248 tons / year. A ranking in order of importance of these emissions places the region of Casablanca-Settat in first place with around $24.8 \%$, followed by the region of Rabat-Salé-Kénitra with $13.4 \%$, by the region of Marrakech-Safi with $13.2 \%$, of the region of Fès-Meknes with $11.8 \%$, then the Region of Tangier-Tétouan-Al Hoceïma with $10 \%$. The other regions represent around $26.6 \%$ of the total $\mathrm{CO}_{2 \mathrm{e}}$ equivalent emissions. If the landfill gas methane is burned, the total carbon dioxide emission is only about 545
911 tons / year, a reduction in total greenhouse gas emissions of about $89 \%$. This will on the one hand replace fossil fuels with a cheap source of energy, and on the other hand fight against global warming and limit in the long term the impact on climate change.

This is an Open Access article distributed under the terms of the Creative Commons Attribution License.

\section{References}

1. IPCC (2013): Climate Change 2013: The Physical Science Basis. Contribution of Working Group I to the Fifth Assessment Report of the Intergovernmental Panel on Climate Change. Cambridge University Press, Cambridge, United Kingdom and New York, NY, USA, 1535 pp. Available from: https://www.ipcc.ch/report/ar5/wg1/.

2. EPA (2005a): Inventory of U.S. greenhouse gas emissions and sinks: 1990-2004. Methodology for estimating CH4 emissions from landfills, USA (2005).

3. EPA (2005b): United State Environmental Protection Agency (US EPA) (2005b). Landfill Gas Emissions Model (LandGEM). Version 3.02 , USA (2005).

4. IPCC (2006): Intergovernmental panel on climate change (IPCC). 2006 GIEC Guidelines for National Greenhouse gas Inventories Volume 5 Waste, Chapter 3, Solid Waste Disposal. In Good Practice Guidance and Uncertainly Management in National Greenhouse Gas Inventories. Site http:/www.ipbbnggip.igesor.jp/public/2006gl/vol5.html.

5. HCP (2015): Haut-Commissariat au Plan (HCP), Recensement général de la population et de l'habitat de 2014 - Population légale au Maroc. Bulletin officiel $N^{\circ}$ 6354, ISSN 0851 - 1195, Avril (2015).

6. https://fr.climate-data.org/afrique/maroc-181/

7. Thornthwaite, C. W. "An Approach toward a Rational Classification of Climate.” Geographical Review, vol. 38, no. 1, 1948, pp. 55-94. JSTOR, www.jstor.org/stable/210739.

8. HCP (2017): Haut-Commissariat au Plan (HCP). Projections de la Population des Régions et des Provinces 2014-2030. Centre d'Etudes et de Recherches Démographiques (CERED), Maroc, Mai (2017). Site https://www.hcp.ma/region-drta/attachment/861124/

9. MEMDD (2019): Secrétariat d'Etat auprès du Ministère de l'Energie, des Mines et du Développement Durable (MEMDD),
Stratégie Nationale de Réduction et de Valorisation des Déchets. Rapport de synthèse, 20 pages, Maroc, Mars (2019).

10. Naimi Y., Saghir M., Cherqaoui A. and Chatre B. (2016), Energetic recovery of biomass in the region of Rabat, Morocco. International Journal of Hydrogen Energy. DOI: 10.1016/j.ijhydene.2016.07.055, (2016).

11. Adnani D. (2006): Gestion déléguée du service publique : Cas de l'assainissement solide (2006). In http://adnanidriss.centerblog.net.

12. Soudi B. and Chrifi H. (2008): Option de gestion des déchets solides municipaux adaptés aux contextes des pays du sud. Enda Maghreb (2008).

13. El Maguiri A., Souabi S., El Fels L., El Asli A. and Hafidi M. (2017): Progress in establishing an ambitious domestic waste management scheme in Morocco - A model for developing countries. In Municipal Solid Waste. Ed: Nikolaos Tzortzakis. ISBN: 978-153611-865-0. Nova Science Publishers, Inc. (2017).

14. GIZ (2014): Sweep-Net, Country report on solid waste management in Morocco. Bonn and Eschborn: Deutsche Gesellschaft für Internationale Zusammenarbeit (GIZ) GmbH (2014).

15. IPCC (1996): Intergovernmental Panel on Climate Change (IPCC), Revised 1996 GIEC Guidelines for National Greenhouse gas Inventories. Reference manual Volume 3, Chapter 6 Waste. Site https://www.ipcc-nggip.iges.or.jp/public/gl/invs 1.html.

16. IPCC (1990): First Assessment Report (AR1) of the Intergovernmental Panel on Climate Change (IPCC), www.ipcc.ch (1990).

17. IPCC (2007): Forth Assessment Report (AR4) of the Intergovernmental Panel on Climate Change (IPCC), www.ipcc.ch (2007).

18. ADEME (2019) : Documentation des facteurs d'émission de la Base Carbone, Agence de l'Environnement et de Maitrise de l'Energie. Version 16.1.0 (2019). 